\section{Deponienachsorge - ein wichtiger Faktor hinsichtlich Kostenwahrheit in der Abfallwirtschaft}

Deponien als Senken für Stoffe, die aus ökologischen oder ökonomischen Gründen nicht rezirkuliert werden können, stellen ein notwendiges Element jeder nachhaltigen Volkswirtschaft dar. Auch in Zukunft wird man trotz Abfallvermeidung und weitgehender Verwertung auf den Gebrauch von Deponien nicht verzichten können. Gemäß dem Ziel „Nachsorgefreiheit“ des österreichischen Abfallwirtschaftsgesetzes (AWG) sollen Deponieemissionen ein umweltverträgliches Maß sowohl kurz- wie auch mittel- und langfristig nicht überschreiten. Sämtliche Deponien, die in der Vergangenheit angelegt wurden, bedürfen jedoch einer Bewirtschaftung und Überwachung, die sich zeitlich über das Ende der Einbringung von Abfällen erstreckt. Die erforderliche Dauer und Intensität dieser Bewirtschaftung (Nachsorge) wird primär von der biogeochemischen Zusammensetzung der abgelagerten Abfälle, sekundär auch von der Hülle und der Umwelt bestimmt.

Während in der Vergangenheit die Kosten der Deponienachsorge bestenfalls in volkswirtschaftlichen Kosten-Nutzen-Analysen Berücksichtigung fanden, wurde durch die Einführung der Deponiesicherstellung erstmals auch auf betriebswirtschaftlicher Ebene der Tatsache Rechnung getragen, dass die Bewirtschaftung einer Deponie über das Ablagerungsende hinausgehen muss. Derzeit werden gemäß den Vorgaben der Europäischen Deponierichtlinie finanzielle Rückstellungen für einen Nachsorgezeitraum von 30 Jahren gefordert, und zwar unabhängig vom Emissionspotenzial der abgelagerten Abfälle. Im Sinne der Transparenz und Kostenwahrheit wäre der Sicherstellungsbetrag jedoch an die erwartbare Nachsorgedauer und deren Intensität anzupassen. Dies würde im Konkreten bedeuten, dass Deponien mit wenig reaktiven Abfällen (z. B. Baurestmassen) geringere finanzielle Rücklagen für die Nachsorge benötigen als jene mit reaktiveren Abfällen (Restmüll, Rückstände aus der mechanisch-biologischen Abfallbehandlung). Unterschiede in der Qualität der abgelagerten Abfälle würden sich demnach in ungleichen spezifischen Deponierungskosten widerspiegeln. Teure Entsorgungsoptionen, die unter relativ hohen Behandlungskosten ein weitgehend „inertes“ Deponiematerial erzeugen, wären dadurch wirtschaftlich konkurrenzfähig.

Die Internalisierung der Kosten aus der Deponienachsorge, die sich bei Hausmülldeponien über einen Zeitraum von Jahrhunderten erstrecken kann, hätte nicht nur den Vorteil, dass die volkswirtschaftlich günstigste Lösung gewählt wird. Sie würde auch die Gefahr reduzieren, dass Umweltbelastungen aus Deponien an die folgenden Generationen weitergegeben werden, und damit entscheidend zur Erreichung der Ziele des AWG beitragen.

Um die Dauer der Deponienachsorge und damit verbundene Kosten quantitativ bewerten und somit internalisieren zu können, ist ein Verständnis des Deponiekörpers und der Wechselwirkung mit seiner unmittelbaren Umgebung unabdingbar. Im vorliegenden Heft der ÖWAW werden diese und weitere Fragen der Deponienachsorge mit der Absicht untersucht, einen wichtigen Beitrag zur Kostenwahrheit in der Abfallwirtschaft zu leisten.

\author{
Univ.-Ass. DI Dr. Johann Fellner / o.Univ.-Prof. DI Dr. Paul H. Brunner \\ Technische Universität Wien \\ Institut für Wassergüte, Ressourcenmanagement und Abfallwirtschaft \\ Karlsplatz 13, 1040 Wien \\ j.fellner@iwa.tuwien.ac.at / paul.h.brunner@iwa.tuwien.ac.at
}

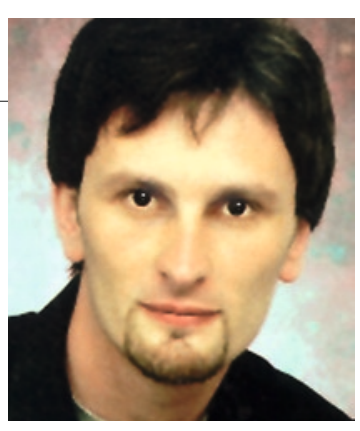

Univ.-Ass. DIDr. Johann Fellner

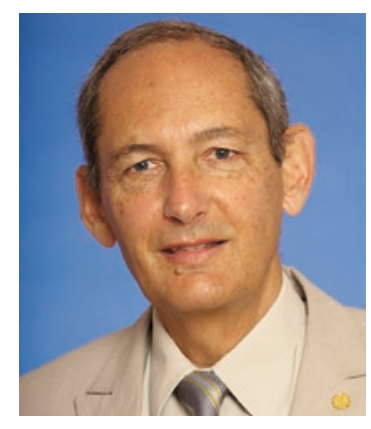

o.Univ.-Prof. DIDr. Paul H. Brunner 